\section{Identical pentapeptides with different backbones}

SIR-In a comment on a recent News and Views article by Harrison', Fasman ${ }^{2}$ maintains that we drew a false conclusion from the finding of identical pentapeptides with different backbone configurations ${ }^{3}$. $\mathrm{He}$ also gives the impression that his algorithm is capable of correctly predicting the secondary structure of such identical pentapeptides, as it takes into account the different neighbouring sequences on both their amino and carboxyl termini.

Contrary to Fasman's point of view, we believe that the strictly hierarchical approach of first predicting secondary structure segments, then tertiary structure by interaction of those segments, cannot succeed. There is a strong feedback component from the tertiary structure. This is clearly demonstrated in the case of bovine and porcine pancreatic phospholipases ${ }^{4.5}$. Here, a segment of 13 amino acids differing only in one position ( $\mathrm{Val} / \mathrm{Phe}$ ) assumes quite different conformations in the two closely related enzymes:

Bovine: ...LDSCKVLVDNPYT...

Porcine: ...LDSCKFLVDNPYT... while the flanking sequences have the same conformation in both structures.

In conclusion, it has never been our intent to discredit predictive schemes but to point out their limitations $s^{6}$ and caution against overinterpretations. Hopefully, awareness of the difficulties of protein structure prediction will lead to real progress.

WOLFGANG KABSCH Chris SANDER

\section{Max-Planck Institut für}

medizinische Forschung,

\section{Heidelberg,}

Jahnstrasse 29, FRG

1. Harrison. S. Nature 313.736-737 (1985)

2. Fusman. G.D. Nature 316. 22 (1985)

3. Kabsch, W. \& Sander. C. Proc. nutn. Acad. Sci. U.S. A. 81 1075-1078 (1984).

4. Dijkstra, B.W.. Weijer. W.J. \& Wierenga. R.K. FEBS Lett. 164. 25-27 (1983).

5. Lesk. A.M. BioEssavs 2, 213-214 (1985).

6. Kabsch, W. \& Sander, C. FEBS Lett. 155, 179-182 (198,3).

\section{Haldane's rule $\mathrm{OK}$, but not always}

SIR-In a recent article', Haldane's rule "When in the $F_{1}$ progeny of two animal races one sex is absent, rare, or sterile, that sex is the heterozygous (heterogametic) sex" , was lauded as surviving, presumably unblemished. It has been confirmed for mammals, birds, butterflies and snakes' and insects ${ }^{3}$. Nonetheless, a good rule need not be without exception.

In North America, certain populations of the mole salamander (genus Ambysto$m a)$, the female of which is the heterogametic (WZ) and the male the homogametic $(\mathrm{ZZ}) \mathrm{sex}^{4.5}$, exist as combinations of sympatric species and their hybrids. These complexes consist of naturally occurring diploid, triploid and tetraploid individuals and such populations have been labelled unisexual, for in all those examined ( $A$. laterale-jeffersonianum ${ }^{6}, A$. jeffersonianum-texanum,$\quad A$. lateraletexanum $^{8.9}, A$. nothagenes ${ }^{10}$ ) males have either yet to be found, or at most form $5 \%$ of the population. Of the few reported males, three have been triploid and the rest diploid. Laboratory reared offspring from eggs of diploid and polyploid females have all been female ${ }^{6}$. The rarity of males in these hybrid complexes contrasts strongly with the normal $1: 1$ sex ratio or even preponderance of males in nonhybrid ambystomid populations".

The rarity of males has prompted some authors to propose a parthenogenetic ${ }^{7.8}$ or gynogenetic ${ }^{6}$ mode of reproduction but we have shown that at least on Pelee Island (Lake Erie, Ontario), sperm is needed and incorporated into gametes of female $A$. laterale-texanum. Unreduced eggs of these hybrid females combining with haploid sperm produce the observed triploid and tetraploid animals. Unreduced eggs in a "dominant W" sex determination system will lead to mostly females ${ }^{4.5}$ as found, but diploid females should produce males in a minimum of $3 \mathrm{~F}: 1 \mathrm{M}$ ratio.

In hybrid Ambystoma, males, the rare or absent sex, are homogametic. Although there is reduced hatching success in eggs from hybrid females ${ }^{12.6}$, triploid and even tetraploid hybrid females are fertile. In this early stage of our investigations, we conjecture that $\mathrm{Z}$-containing gametes from diploid (WZ), $\mathrm{Z}$ or $\mathrm{ZZ}$ gametes from triploid (WWZ, WZZ) and Z, $\mathrm{ZZ}$, or $\mathrm{ZZZ}$ gametes from tetraploid (WWWZ, WWZZ, WZZZ) females are rarely produced, are not viable, or that most larvae homozygous for $\mathrm{Z}$ and therefore destined to be males, do not survive. The virtual absence of polyploid males is explainable as a consequence or unreduced eggs from the $W$ carrying females, but the number of diploid male hybrids is far lower than expected. It appears that in ambystomid salamanders, males may be innately more sensitive to the effects of interspecific hybridization than are the females, an explanation rejected by $\mathrm{Hal}-$ dane himself.

\section{Department of Biology,}

LAWRENCE E. Licht

\section{York University.}

Toronto, Ontario,

Canada M3J 1 P3

Department of Zoology,

JAMES P. BOGART

University of Guelph,

Guelph, Ontario,

Canada NIG 2WI

1. Jones. J.S. \& Barton. N. Nature 314. 668-669 (1985)

2. Haldane. J.B.S. J. Genet. 12. $101-109$ (1922)

. Covne, J.A. Nature 314. 736-738 (1985)

4. Humphrey. R.R. Am. J. Anat. 76 33-66 (1945).

5. Seesions. S.K. Chromosome 84, 599-621 (1982)

6. Uzzell. T.M. Jr Copeia 1964. 257.301) (1964.

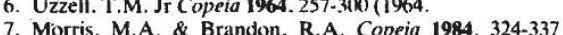
(1984).

8. Downs. F.L. Occas. Pap. Mus. Zool. Univ. Mich. 685, 1-36 (1978)
9. Bogart. J.P.. Licht. L.E.. Oldham. M.S. \& Darbyshire. S.J. Can. J. Zool. 63. 340-347 (1985)

0. Kraus. F. Occas. Pap. Mus. Zool. Univ. Mich. 709. 1.24 (1985)

11. Husting. E. L. Copeia 1965, 352-362 (1965).

12. Piersol. W. A. Am. Nat. 44. $732-738(1910)$

\section{Dating of craters and extinctions}

SIR-Recently Weissman' discussed the topic of periodicity in the geologic record of extinctions and craters. The weakest correlation in his work is the late Ordovician extinction, for which his Fig. 1. shows no craters $\geqslant 10 \mathrm{~km}$ and only one $>5 \mathrm{~km}$ in diameter. On or about the same date I reported $^{2}$ the finding of iridium in breccias of Jeptha Knob, Kentucky and suggested that the $\sim 2 \mathrm{~km}$ feature could represent the central peaks of a larger $(\sim 20 \mathrm{~km}$ ?) complex crater. If this latter is true, because Jeptha Knob has intensely deformed Upper Ordovician rocks beneath undeformed Silurian cap-rocks, the correlations on Weissman's Fig. 1 would seem much better. Note also that the Glasford Disturbance, Illinois ${ }^{3}$, similar to Jeptha Knob but completely buried, is of the same age.

Many cryptoexplosion structures are poorly dated, but where their ages can be determined they should be included in the arguments for or against periodicity. Unfortunately, all in Grieve's ${ }^{4}$ list probably fail in size or in dating, although it is not clear which, if any cryptoexplosion structures are included in Weissman's Fig. 1.

C. Ronald SEEger Department of Geography and Geology, Western Kentucky University,

Bowling Green,

Kentucky 42101, USA

\section{Weissman. P.R. Nature 314, 517-518 (1985) \\ Seeger, C.R. Asaro, F. Michel. H.. Alvarez. W. \& Alvarez, L. Lumar planet. Science 16, 757-758 (1985). \\ 3. Buschbach. T.C. \& Ryan. R. Bull. Am. Ass. Petrol. Geol. 47, 2015-2(1)22(1963) \\ 4. Grieve. R.A.F. Geol. Soc. Am. spec. Pap. 190. 25-37 (1982).}

\section{Icosahedral packaging of spheres}

SIR-I wish to question the accuracy of the statement in A.L. Mackay's excellent letter (Nature 315, 636; 1985) that the central space of icosahedrally packed spheres will accommodate a sphere with $95 \%$ of the radius of the others.

If the outer spheres are of unit diameter, then their centres form an icosahedron whose side is unity. The circumradius of that icosahedron is $5^{1 / 4} \cdot \tau^{12} / 2$ where $\tau$ is the Golden mean $\left(\left(5^{12}+1\right) / 2\right.$ $=1.618033989$ ). Thus the circumradius is 0.951056517 . Since the outer spheres have a radius of 0.5 then the inner sphere has a radius of $(0.951056517-0.5)=$ 0.451056517 . This gives it a diameter of 0.902113034 and this is $90.2 \%$ of the outer spheres".

It is of interest that the 12 spheres of the outer shell can be close packed in a 'dyma- 